\title{
La arquitectura natural del habitar
}

\author{
Esther Ferrer Román y Francisco Montero Fernández \\ Universidad Europea de Canarias; Universidad de Sevilla \\ estudio@esferoarquitectura.com; fmontero@us.es
}

RESUMEN: La arquitectura como refugio, como construcción de un hábitat capaz de dar respuesta a las necesidades de quien la habita permite pensar en la posibilidad de aprender de la manera intuitiva en que ciertos animales construyen sus refugios como arquitecturas propias. Seres que se cobijan en la naturaleza siguiendo diversas pautas, construyendo espacios habitables que, en algunos casos, prestan atención al entorno como mejor aliado. En otros casos los animales se apoyan en lo existente y, a veces, excavan la tierra para encontrar cobijo, pero otros son capaces de tomar restos del entorno o producir materiales artificiales para construir su refugio. Podemos advertir que las estrategias utilizadas por el mundo animal para la configuración de sus cobijos se asemejan a las del hombre a la hora de construir e imaginar nuevos espacios habitables.

PALABRAS CLAVE: Hábitat sostenible; Refugios; Arquitectura y naturaleza; Arquitecturas mínimas; Arquitectura y animales.

\section{The Natural Architecture of Inhabiting}

ABSTRACT: Architecture as a refuge, as the construction of a habitat capable of responding to the needs of those who inhabit it, allows us to consider the possibility of learning from the intuitive way in which certain animals build their refuges as their own architectures. Beings that take shelter in nature following diverse guidelines, constructing habitable spaces that, in some cases, use their surroundings as their best ally. In other cases the animals rely on what is already there and, sometimes, dig the earth to find shelter, while others are able to take remains from the environment or produce artificial materials to build their shelter. We can observe that the strategies used by the animal world for the configuration of their shelters are similar to those of man when it comes to building and imagining new habitable spaces.

KEYWORDS: Sustainable Habitat; Shelters; Architecture and Nature; Minimal Architecture; Architecture and Animals.

Recibido: 28 de febrero de 2019 / Aceptado: 12 de mayo de 2019.

Al pasear por la costa en una bajamar, no hay nada más difícil que intentar capturar un cangrejo al borde de una roca. Al acercamos el animal parece disminuir su grosor y encontrar cobijo en alguna oquedad de la piedra, pero en la mayoría de los casos, el hueco en el que se cobija tiene la misma dimensión que la del animal, apenas existe separación entre él y el límite interior de la oquedad. La forma del hueco atiende a un mundo de lateralidades, en el que uno de los ejes de la dimensión horizontal toma protagonismo frente a la vertical. El constante batir de las aguas erosiona las grandes rocas en las que toman cobijo, excavando huecos más profundos que anchos, por lo que estos animales apenas deben hacer nada, simplemente buscar el lugar más adecuado para su dimensión. Los animales solo tienen que guardar su envergadura, recoger parte de sus patas, acercar todo lo que sobresalga de su concha justamente a ella y encajarse en el hueco elegido, llenando el espacio antes vacío. Aprendiendo de la situación del cangrejo, podemos reconocer que esa primera arquitectura nace en la mirada de quien la busca, que es capaz de descubrir un hueco o un vacío que se convierten en el espacio perfecto para cobijarse, más allá de la conciencia de su propia forma. A partir de esta valoración podríamos preguntarnos por el espacio mínimo en el que habitar.

En la escala urbana, nuestras ciudades parecen haber perdido la conciencia de la dimensión humana. El crecimiento frenético que han padecido nuestras urbes en los últimos tiempos mutila esa dimensión mínima que sutilmente nos muestran los cangrejos en los días de verano en la playa. En nuestras ciudades no cabe el espacio de apropiación, sin embargo

Cómo citar este artículo: FERRER ROMÁN, Esther y MONTERO FERNÁNDEZ, Francisco, "La arquitectura natural del habitar», Boletín de Arte-UMA, n. ${ }^{\circ} 40$, Departamento de Historia del Arte, Universidad de Málaga, 2019, pp. 147-158, ISSN: 0211-8483, e-ISSN: 2695-415X, DOI: http://dx.doi.org/10.24310/BoLArte.2019.v0i40.5715 
los homeless se hacen de un carro de supermercado para desplazar sus viviendas itinerantes, casi como si de la concha de un caracol de mar se tratase, la mudan cuando encuentran otra mayor y de mejor cualidades, pero la ciudad parece que no tiene nada que decir sobre ellos y su existencia es paralela a uno de los defectos más notorios de nuestra evolucionada cultura urbana, pero realidades de nuestros entornos cotidianos.

Los bancos, aunque solo aquellos que no tienen un brazo en el medio para interrumpir su longitud, son a veces esos espacios mínimos idóneos para quien parece no tener espacio en nuestras urbes. Separadas de la humedad del suelo tienen una curvatura, no demasiado incómoda, como para dejar descansar el cuerpo itinerante que durante el día recorre la ciudad. Sería fantástico que existieran estructuras asociadas a esos bancos urbanos que pudieran dar también techo a las personas que durante la noche no tiene otro sitio en el que vivir. Quizás podrían ser un textil que replegado en un borde del banco dejase ver su verdadera dimensión cuando acoge al asiento y a aquel que pretende habitarlo durante la noche. En este caso el homeless, como el cangrejo, tendería a rebajar su dimensión, pegaría sus piernas, sus brazos los llevaría al tronco y entonces una efímera estructura lo acogería, configurando un espacio nómada que transportado por el homeless se integraría en el banco elegido.

\section{Refugios urbanos: apropiaciones voluntarias}

Durante años una anciana estuvo viviendo durante el día en el portal de una casa abandonada en el centro histórico de Sevilla. Ese portal se encontraba a menos de 200 metros de un Centro de Salud, y justo en frente de una de las escasas fuentes de agua potable que existen en la ciudad andaluza. La anciana había encontrado, como el cangrejo en la roca, una oquedad. Aquella anciana no permitía que le diesen dinero, realmente no lo necesitaba y tenía sus posesiones, incluso leía revistas de moda y sus cartones sin publicidad indicaban que eran comprados para poder acomodar su refugio. Su oquedad estaba construida a partir de una opción de vida. Sus circunstancias habitacionales eran consecuencia de una decisión personal: ella había decidido vivir de aquella manera, apropiándose del lugar, incluso nos hizo sospechar a todos que aquella fuente de agua potable que había surgido frente al portal había sido financiada por la anciana.

Esa misma puesta en valor de una decisión vital, de la elección de una opción que determina una manera de vivir alternativa, la podemos observar en la iniciativa en 1985 que Toyo Ito propone cuando nos ofrece los proyectos $P A O$ para las muchachas nómadas de Tokio, proyectos que son pensados como reflejo tecnológico de la envolvente de una acción.

El mito de la cabaña primitiva construida por los hombres que dejan de ser nómadas, en un claro del bosque, ha dado pie a la idea de que la arquitectura, negociando con las piedras, ramas y hojarasca, tenía por objeto el montaje físico y material de estos refugios. Pero son pocos los que, superando la pereza, han seguido leyendo el Libro I de Vitrubio y, unas líneas más adelante, han comprobado que, para el arquitecto romano, aquella construcción no se definía por la materialidad de sus componentes físicos, sino por el hecho de que la arquitectura era, debía ser, el lugar en el que se produciría el nacimiento del fuego y de la palabra. Ninguna cosa física, material, tangible, por tanto, sino la inmaterialidad de la energía de la comunicación es, desde Vitrubio, el verdadero material de la arquitectura (De Solá, 2000: 10).

Como comenta la doctora arquitecta Luisa Alarcón (Alarcón, 2015: 295 y ss.) se trata de un proyecto que muestra un concepto de casa disperso por la ciudad, donde las habitaciones se han diluido en el espacio público y que el propio Toyo Ito define como la vivienda (Pao) para una muchacha que vive sola y vaga por la inmensa llanura de los media llamada Tokio. En la ciudad contemporánea fundamentalmente extensa, donde los ciudadanos se han vuelto nómadas de ese territorio, estas propuestas definen una nueva posibilidad de definir una arquitectura específica, que permita habitar lugares intermedios, móviles vinculados a unas jornadas con demasiado tiempo dedicado al transporte. Lugares de oportunidad construidos y llenos de intencionalidad.

Si miramos desde los ojos de aquel que busca cobijo podemos encontrar residuos, lugares alejados de la mirada más administrada que funcionan como oquedades. Viviendas cuyos techos tienen más de 50 metros de luz. Quizás, justo por su gran dimensión, no sea el lugar idóneo en el que un cangrejo tomaría cobijo, pero las estructuras de los puen- 


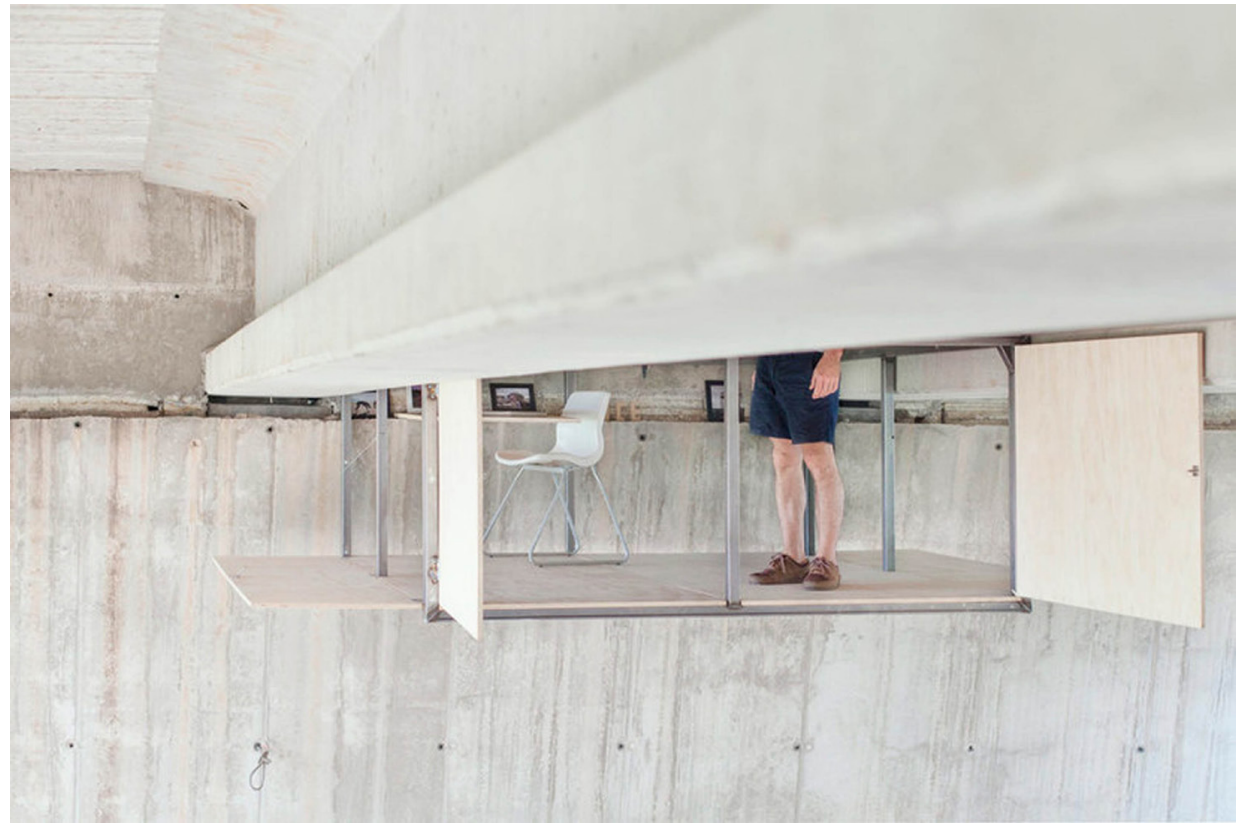

1. Instalación de Fernando Abellanas. Autor imagen: José Manuel Pedrajas (Valencia, 2017)

tes tienen espesor, la inercia que necesita el hormigón para poder soportar los esfuerzos a lo largo de esas grandes luces le hace que adquiera unas formas determinadas. Entonces ya no se trata de un plano que hace de techo, sino de unas paredes que en forma de «U» ofrecen inercia a ese techo. Justo ahí, inquietos artistas como Fernando Abellanas [1], se apropian de la estructura. Ahora sus manos y su ingenio dan forma a un pequeño estudio construido entre los pocos huecos existentes en las leyes que rigen estas ciudades tan cerradas.

\section{Excavaciones y acciones sobre la materia}

Hay cangrejos que al no tener cerca ninguna roca se atreven a excavar en la arena. Entonces existe cierta manipulación, pero nuevamente la longitudinalidad determina la dimensión del hueco, es más estrecho y profundo que ancho. Ahora el cangrejo sustrae materia para encontrar cobijo. El material es apto para ser excavado con la concha de la que están hechas sus patas, expulsando al exterior el material sobrante del terreno. Desde dentro nos mira intentando pasar desapercibido. Si llevamos esta mínima forma de manipular la materia, para encontrar un espacio en el que habitar, al mundo de la arquitectura, quizás sea difícil no tener en cuenta el proyecto denominado la Carlinga de Norman Foster [2]. El primer encargo que recibe el equipo Team 4 del que formaba parte el brillante arquitecto.

La Carlinga ofrece un espacio mínimo desde el que ver el estuario del río Fel, pero además es un espacio excavado, camuflado en la naturaleza y proyectado como observatorio de aves. La Carlinga como término nos recuerda el espacio destinado a los pilotos en los primeros aviones o en ultraligeros, un espacio ergonómico que en este caso adquiere una condición arquitectónica, más allá de la simplemente funcional. La construcción integrada de un espacio conjugando soluciones a distintos requerimientos y capaz de formar parte de un lugar, diferencian este proyecto de Foster de la burbuja funcional de cualquier avión.

En este proyecto todas las dimensiones son mínimas y responden, como el hueco del cangrejo, a aquel que la va a habitar. No hay nada que sobre. La tierra es el asiento perfecto, se excava en ella bajo las directrices de las medidas del hombre, si el cangrejo necesita, en la arena, hacer un espacio profundo debido a su anatomía, el hombre necesita de un lugar en el que sentarse, estar de pie o acostado, es por 


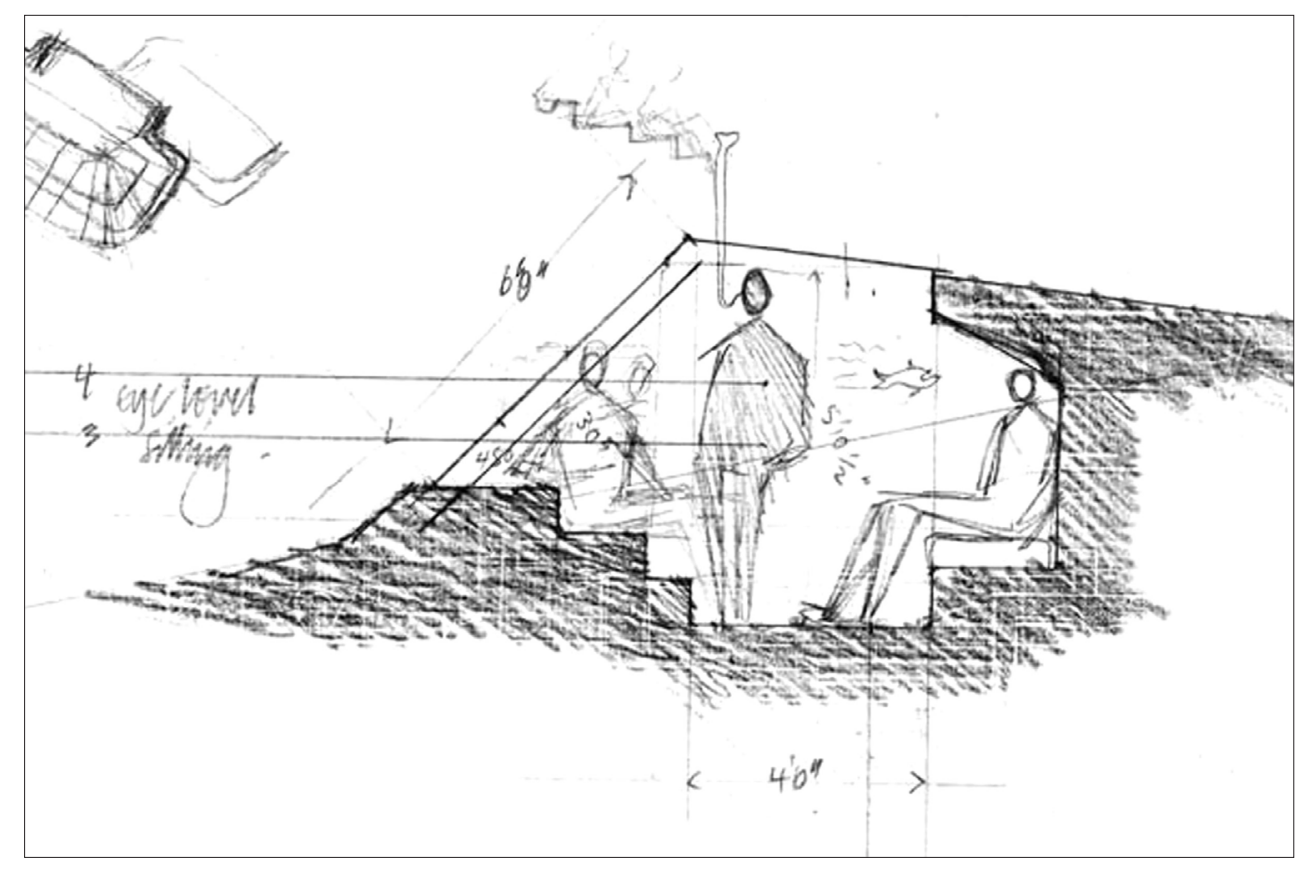

2. Croquis de la Carlinga (the Retreat). Autor proyecto e imagen: Team 4 (1963). En: Casabella, n. ${ }^{\circ} 836$

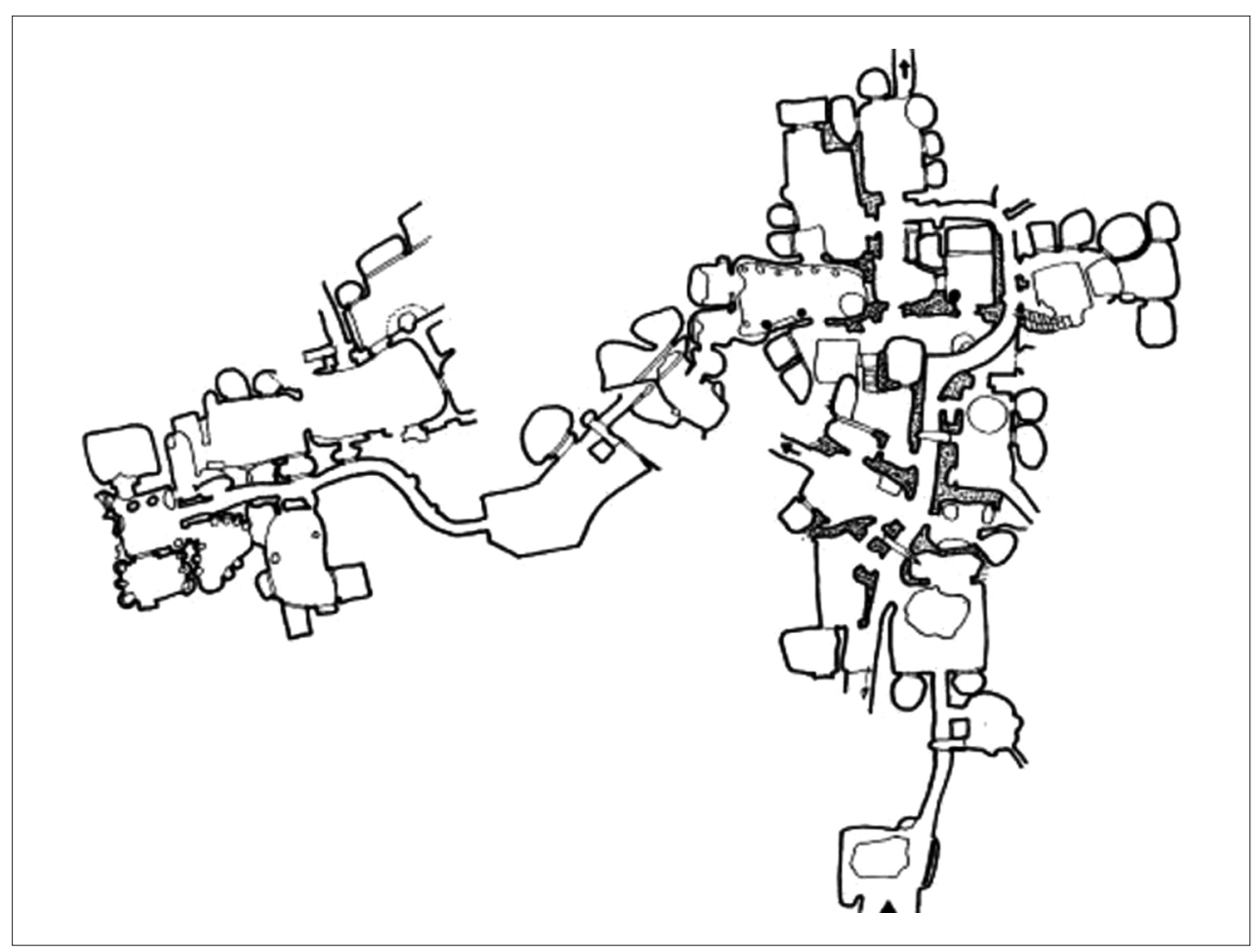

3. Planta de la ciudad de Kaymakli. En: Loubes, 1985, p. 90 


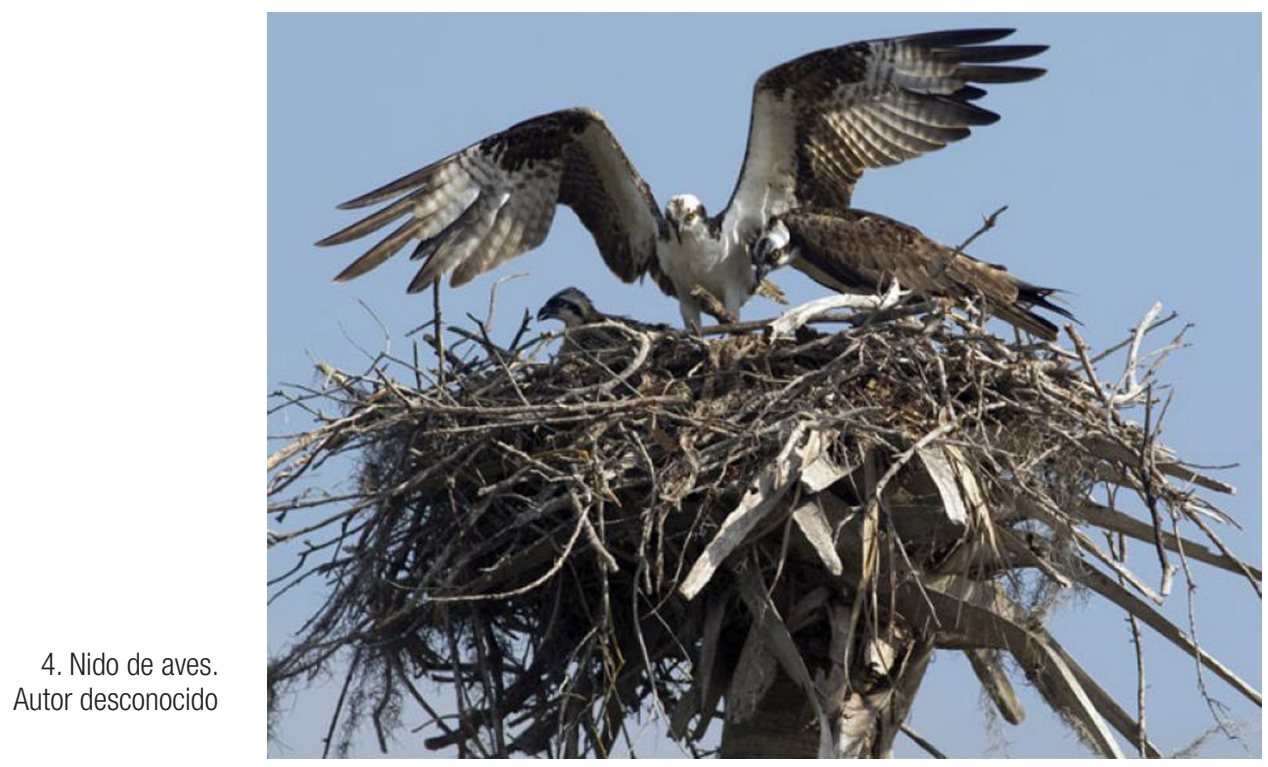

ello por lo que cada uno de los trazos dibujados sobre la tierra responden a las diversas situaciones, así, el mejor lugar desde el que ver estará cobijado, en cierto modo, por el propio material en el que se sienta. La forma exterior de la Carlinga responde al espacio interior excavado.

En la Carlinga la forma de apropiarse de un lugar está relacionada con la manera con la que algunos animales excavan para obtener cobijo, en cambio, en Kaymakli [3], una ciudad excavada situada en la Capadocia, lo está con los nidos de algunas hormigas. Tanto en la ciudad de Kaymakli como en la «ciudad» de las hormigas existe una estructura de caminos y de volúmenes que van creciendo con una cierta continuidad bajo un estricto orden que tiene que ver con las características del terreno. En el caso de las hormigas se ha demostrado que son capaces de trabajar sobre cualquier superficie, simplemente necesitan que esta no tenga una humedad extrema. La densidad del terreno es la que determinará la manera de ejecutar el procedimiento de excavación ${ }^{1}$. En el caso de las arquitecturas primitivas excavadas por el hombre, la dureza del terreno era determinante, la vinculación de la ciudad de Kaymakli al suelo de ceniza de la Capadocia explica su extensión. Por otra parte, tanto en las construcciones de estos animales como en esta arquitectura primitiva el vacío va creciendo progresivamente. A medida que se va necesitando de nuevos espacios en la ciudad, o en el nido, se van aumentando las galerías o los pasillos comunicantes. Formalmente los nidos de hormigas y estas arquitecturas excavadas son, sorprendentemente, muy similares.

El paralelismo entre estos dos mundos nos deja ver las bases más primitivas de la arquitectura, un espacio cuyo origen no se encuentra en el añadido de elementos sino en la construcción de nuevos vacíos a partir de la eliminación de masa, por medio, igualmente, de aspectos muy primigenios. Oquedades o excavaciones, mirada o manipulación.

\section{Refugios y sedimentos}

Pero hay otras muchas maneras en la que los animales nos enseñan a crear espacio. De las más atractivas que existen están aquellas relacionadas con el nido. La hoja que se ha caído, las finas hierbas que quedan secas, las pequeñas ramas que están en el suelo... toman otra vida. Inertes, pasan ahora a ser estructuras en las que lo residual deja de serlo para entonces convertirse en material de creación [4]. La costra es la clave, ya que estas estructuras son el sumatorio de cosas que van tomando forma hasta obtener el espesor deseado. El nido es una estructura sostenible, toma de lo que sobra, de lo que ya no tiene vida para pasar a crear una construcción. En relación a esto no podemos obviar la relación que parece tener con las arquitecturas del límite. Nos 


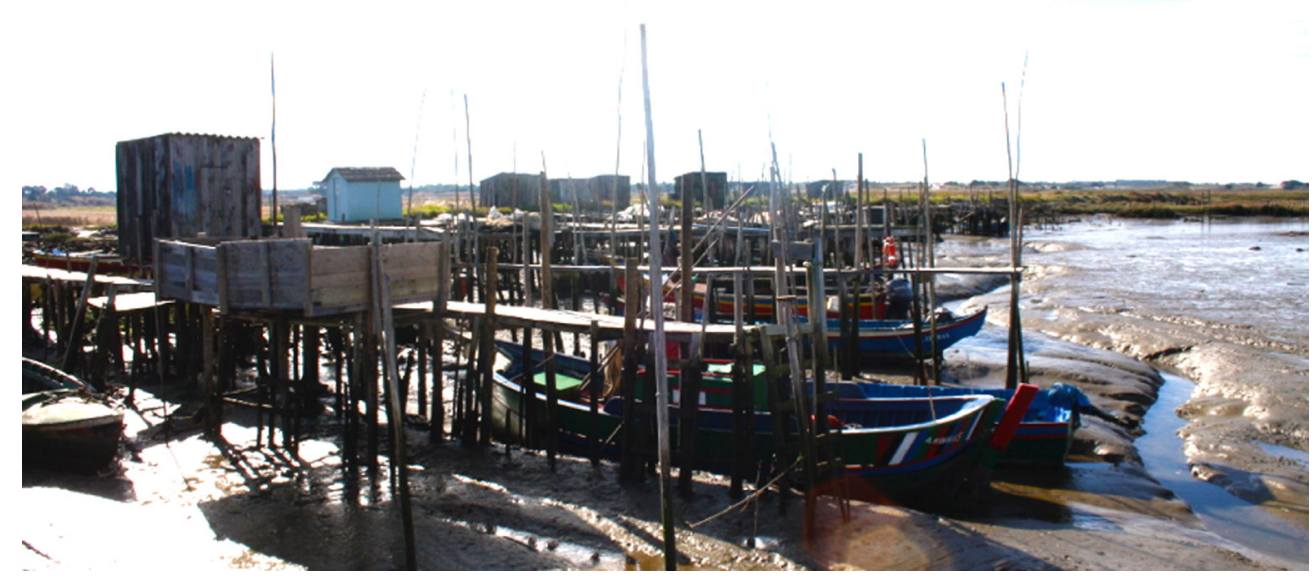

5. Arquitectura del límite. Autor imagen: el autor del texto (Carrasqueira, 2019)

referimos a aquellas asentadas en parajes inaccesibles, en lugares pertenecientes a la tierra, en los que la arquitectura no tiene otra que aprovechar lo residual para poder formarse. Uno de estos casos lo podemos ver por ejemplo en la arquitectura que los poblados de pescadores realizan cerca de los esteros, en los límites de la ciudad de Venecia, en la isla gaditana de San Fernando, entre salinas o en Carrasqueira, Portugal [5]. Una arquitectura vulgarmente conocida como arquitectura de palafitos, fundamentada a partir de las costras de chapas, trastos, chismes, cacharros lanzados al olvido en estos territorios del despojo. En estas arquitecturas, a diferencia de las ofertadas desde la belleza más clásica, el mantenimiento es apenas necesario. El tiempo las embadurna, las hace envejecer, puede que incluso obligue a colocar, como ocurre en los nidos, nuevas costras sobre las ya dispuestas, sin embargo, ni el tipo de material, ni su forma, ni siquiera sus medidas son importantes. Si se termina por romper el palafito que aguanta el pequeño muelle que enlaza estos «enjambres» con el agua, o alguno de aquellos que hacen directamente de base de estas arquitecturas remendadas, simplemente hay que buscar otro palo en los alrededores -puede incluso que quitarlo de otra de estas casetas- y así una vez remachado, solucionar el problema. Aquel que se quita o bien se lanza de nuevo al lugar de donde se recogió o bien - ¿por qué no?- se reutiliza como perchero en otra parte ${ }^{2}$. Esta mezcolanza, al igual que esta liberación en los ideales de belleza, infunde una arquitectura sostenible que busca en las proximidades los materiales con los que ejecutarse. El hombre, una vez olvidado el papel de administrador y gobernador, queda subyugado a este territorio, para ser, como aquellos pájaros creadores de nidos, una especie de contribuyente simbiótico entre el territorio y los residuos existentes en el mismo.

Un nido es la construcción de un espacio afín a la forma de los huevos y del confort de las pequeñas crías. Pero más allá de la configuración de ese espacio principal, la construcción del nido comienza por la elección de un lugar que aporta una forma estructural, un soporte capaz de dar respuesta a varios requerimientos entre los que se pueden encontrar su resistencia y su inaccesibilidad. Elegido el lugar, la acumulación de materiales conforma la construcción de un límite basado en un espesor material que articula la forma estructural del árbol con la forma espacial de su núcleo. Con independencia de cómo las aves formen su nido, el objeto es construir a partir del vacío. Algunos animales, como hemos señalado, acumulan ramas encontradas, los más sorprendentes por su dimensión son los de las cigüeñas, otros conforman su propia Carlinga y excavan en la tierra un hueco suficientemente profundo como para que los huevos no rueden, es el caso de los avestruces o los patos, algunos crean una loma y dentro, bajo unas condiciones de humedad determinada, dejan sus huevos, otros incluso son capaces de formar un nido gracias al barro y a la propia saliva, tal y como las golondrinas, pero todos, con independencia de la forma y el sistema elegido están, como decimos, construyendo un vacío a partir del espesor acumulado. 
6. Planta de las viviendas en María Coronel. Autores: Antonio Cruz y Antonio Ortiz. En: cruzyortiz (web)

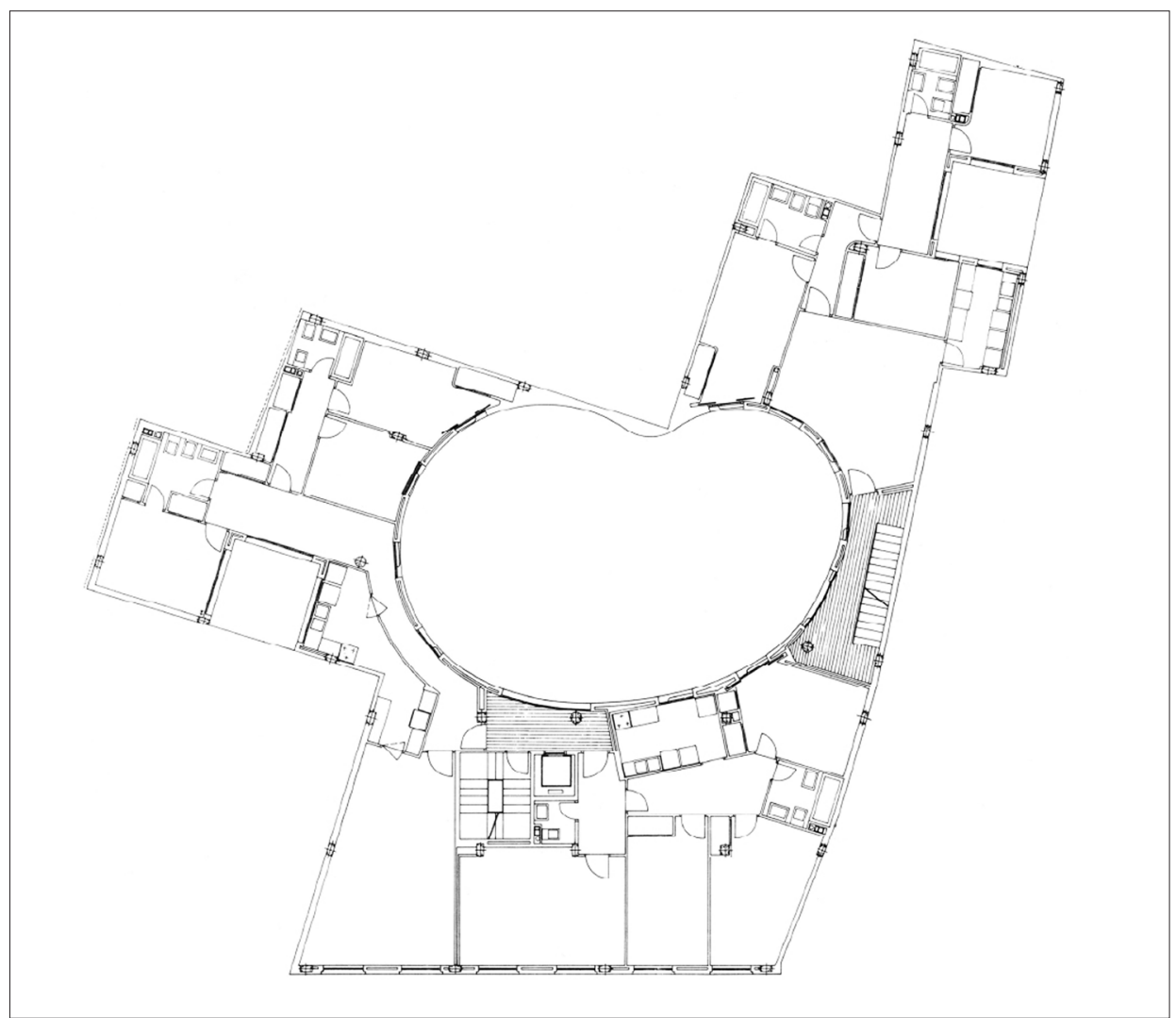

El proyecto de viviendas en calle María Coronel de Sevilla, de los arquitectos Antonio Cruz y Antonio Ortiz [6], ocupa el espacio justamente como lo hace un nido de ave. La ciudad aporta el soporte, la estructura urbana, allí encontraremos la razón de la morfología del solar, la volumetría relativa, los condicionantes de orientación, los contextos a los que atender. Los arquitectos aportaron la idea sensible, capaz de poner en valor estructural el contexto urbano más allá de una ajustada propuesta funcional. La porosidad es una de las cuestiones fundamentales para conseguir la habitabilidad de un edificio. María Coronel está llena de los poros necesarios para conseguir hacer habitables los espacios más privados de las viviendas, pero el proyecto aporta un espacio protagonista, un lugar colectivo, que se ofrece como un pliegue urbano donde todos se miran y que ordena y estructura todas las decisiones perimetrales.

El proyecto se basa, como en esos nidos, en la construcción de un vacío, por lo que los arquitectos no construyen por adición, no es el espesor construido lo que les interesa sino el hueco que se conforma por la masa añadida.
En el caso de las viviendas de Cruz y Ortiz, al igual que en el caso del nido, la forma exterior no es importante, es la interior la que tiene relevancia y nos ubica en el proyecto del espesor como la solución de articulación entre ese espacio central y el perímetro como forma exterior. Sergio Bettini, en su libro El espacio arquitectónico. De Roma a Bizancio nos explica la secuencia que conduce desde el Tolos romano hasta el templo de Minerva Medica o el vestíbulo de la Piazza d'Oro en Villa Adriana. Sergio Bettini explica magistralmente esta secuencia en la que establece el Tolos como el resultado de la construcción de un espacio determinado por su forma exterior, mientras que en Minerva Médica nos encontramos con el proyecto de un espacio interior que, como la Carlinga, determina la forma exterior. Esa secuencia que explica la relación entre forma interior y forma exterior, tiene un momento intermedio y es aquel en el que, como en un nido tal y como hemos descrito el proyecto de María Coronel, la forma interior y la forma exterior de una arquitectura son indiferentes.

Bettini nos expone el caso del Panteón de Roma, más de Adriano que de Agripa, donde podemos reconocer cómo 


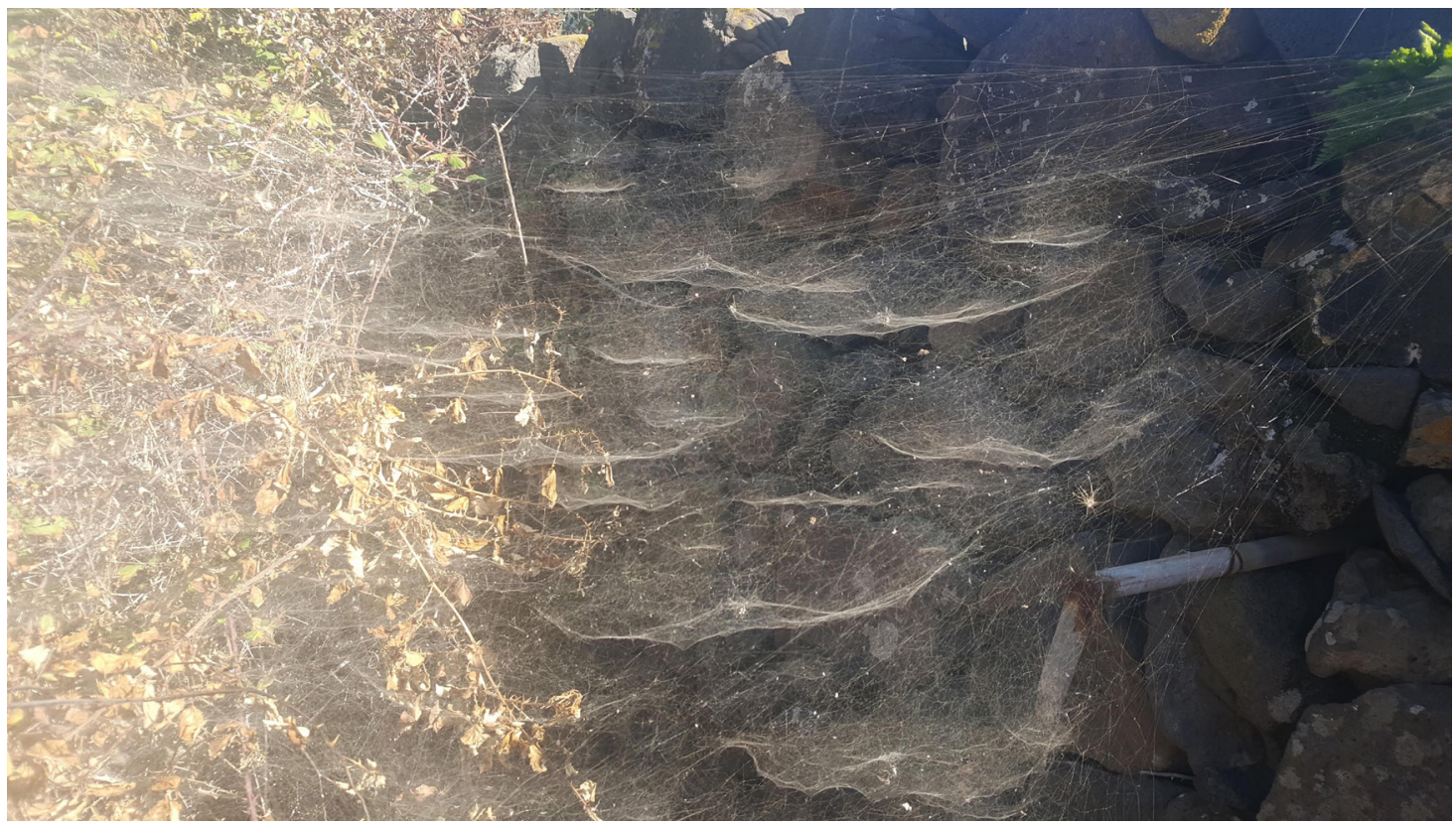

7. Tela de arañas. Autor imagen: el autor del texto (La Orotava, 2019)

el espacio interior se articula con el volumen exterior a través de un espesor considerable gracias al uso de la geometría, el material y la luz, mientras que hacia el exterior nos encontramos con un volumen potente pero sordo.

\section{Refugios flexibles}

Otros animales son capaces de producir material ajeno a lo existente en el entorno para configurar el lugar en el que habitar, es el caso por ejemplo de la araña [7]. En casi todos los casos el punto de partida es muy delicado ya que toda la red de araña nace de unos extremos muy finos que comienzan a ensancharse a medida que la maraña empieza a crecer. Estos extremos son lugares de tensión que nos hacen dudar de la resistencia de la gran maraña dando paso a la imaginación más creativa. El hecho de que la estructura adelgace allí donde toma contacto con el plano del que parte, justamente donde el material debe de tener mayor resistencia, deja a la vista una cierta incongruencia física entre la pesadez y la sección, potenciando así la levedad de la estructura.

La pesada estructura de grandes pórticos de acero de la Galería de las Máquinas construida para la Exposición
Universal de París de 1889 es de los primeros ejemplos arquitectónicos en los que el material parece adelgazar justamente cuando asume las máximas tensiones. Como en el caso de la araña, el material es absolutamente determinante. El acero sustituye a la piedra, y en busca de la mayor eficiencia posible disminuye su sección invirtiendo los procesos constructivos hasta entonces conocidos. La respuesta en la Galería de las Máquinas era funcional y productiva, dejaba ver las grandes ventajas del nuevo material, la articulación estructural, la ligereza, al tiempo que una mayor distancia entre los elementos de apoyo, sin embargo esta nueva forma de construir atentaba también a los sentidos y justamente ese aspecto es el que es utilizado en la arquitectura más contemporánea; la tensión y delgadez del hilo de la araña en su unión con lo existente pasa a ofrecer similares cuestiones a las propuestas por Oscar Niemeyer en su palacio de Congreso en Brasilia. Las esquinas del paño de la cubierta del edificio parecen los extremos de un pañuelo. Este, a través de inventos ocultos a la vista, como en un truco de magia, parece soportar en tirantez el peso de la cubierta inevitablemente expuesta en las cúpulas. El edificio de Niemeyer ofrece fantasía, sorpresa, una atracción inevitable gracias a los secretos que esconden sus estructuras. 


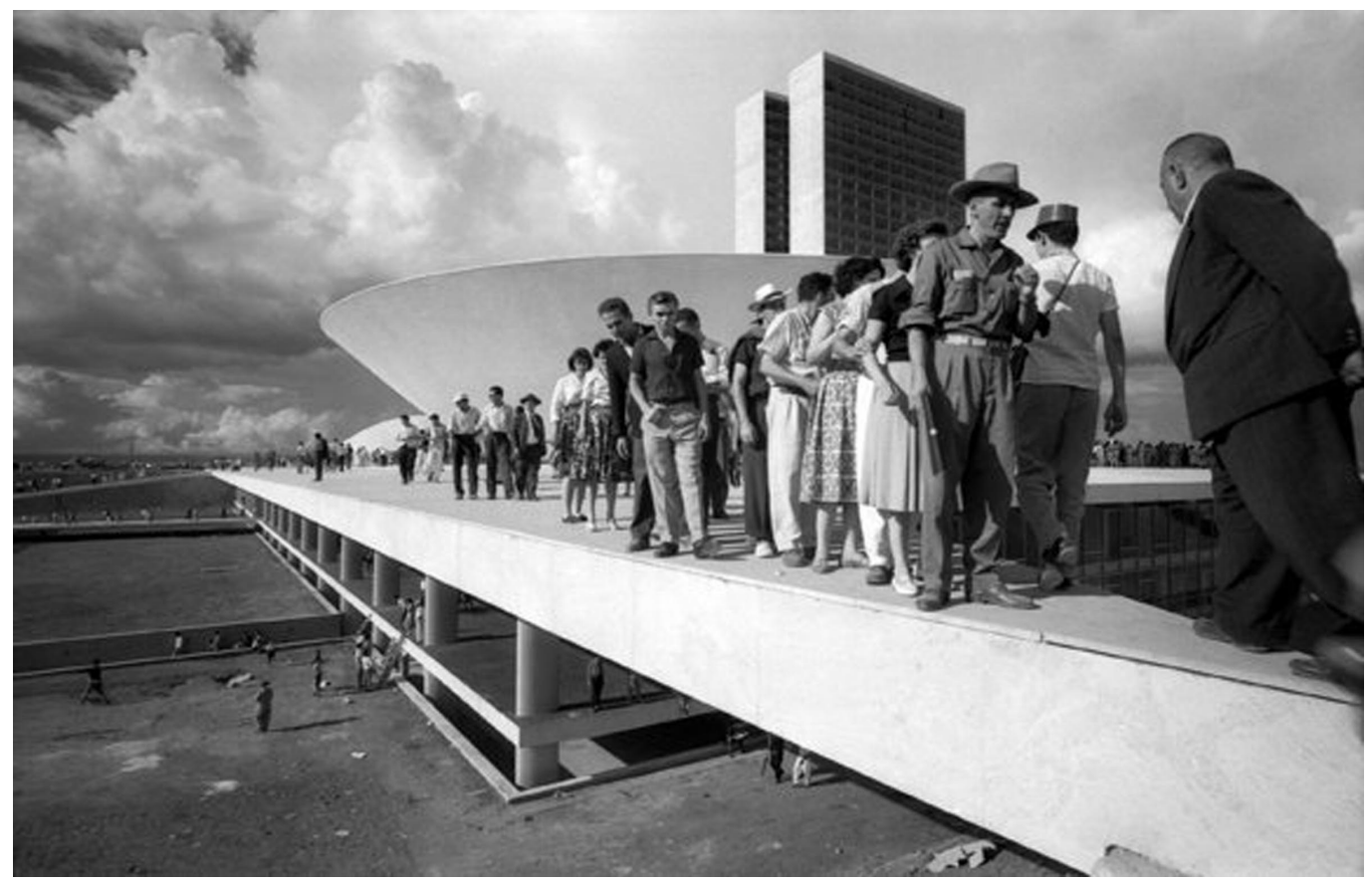

8. Palacio de Congresos de Brasilia. Autor proyecto: Oscar Niemeyer (1960). Autor imagen: Gautherot, M. (Brasilia, 1960)

Hay una fotografía realmente inquietante entre las realizadas por Marcel Gautherot durante la inauguración de Brasilia en 1960: se trata de aquella en la que los visitantes entran y salen de la plaza que forma el edificio [8]. Por una de esas esquinas que se estrechan para disminuir en lo posible el contacto de la plaza con los planos colindantes, las personas, al igual que el edificio, tientan al equilibrio. El instante atrapado por el ojo mecánico del fotógrafo es una imagen que extrema la tensión para dejar paso a la imaginación. Gautherot nos muestra el punto de máxima tensión del conjunto. Los puntos extremos del pañuelo no tocan el suelo colindante, dejando que se contaminen de una tensión extrema que no solo se contempla, sino que, tal y como nos enseña Gautherot, se experimenta. Mientras que la rampa ofrece una entrada pausada y paisajística, el acceso, desde los picos del pañuelo, dirigen la mirada hacía el suelo, el paisaje desaparece para concentrar el ojo en el filo de las estructuras sobre las que, como aquella araña equilibrista, hacemos pie.

La tela de araña nos enseña esa desvinculación de la razón en los puntos de máxima tensión, pero también aspectos que tienen que ver con las capas que separan el interior del exterior en un recinto. El material es traslúcido al tiempo que flexible ya que asume los movimientos que pueden darse en el interior de la propia tela. La tela de araña se convierte, en cierto modo, en una fantástica envolvente. Una envolvente capaz de asumir -¿por qué no?- el decrecimiento o crecimiento del propio edificio que envuelve. Debemos de tener en cuenta que nuestra sociedad es cambiante, apenas existen aspectos constantes en el tiempo. En la mayoría de los casos los contratos son temporales y aquel que los realiza está pensando en cambiar en cuanto se presente la oportunidad. Nuestra economía crece y decrece con la misma facilidad con la que cambiamos de ropa o desechamos el último móvil que hemos comprado cuando llega al mercado uno de nueva generación. Todo parece cambiar, repetirse, desecharse por completo o inventarse de nuevo. Existe una mutación constante aunque nuestra arquitectura parece pensarse desde los paradigmas de tiempos pasados.

En una tela de araña formada por varias arañas, como aquella de la imagen [7], podemos ver cómo el telar aumenta a medida que participan en su conformación más arañas. Por otra parte, cuando una presa queda atrapada en la red la araña multiplica el material para envolverlo, la tela crece, 


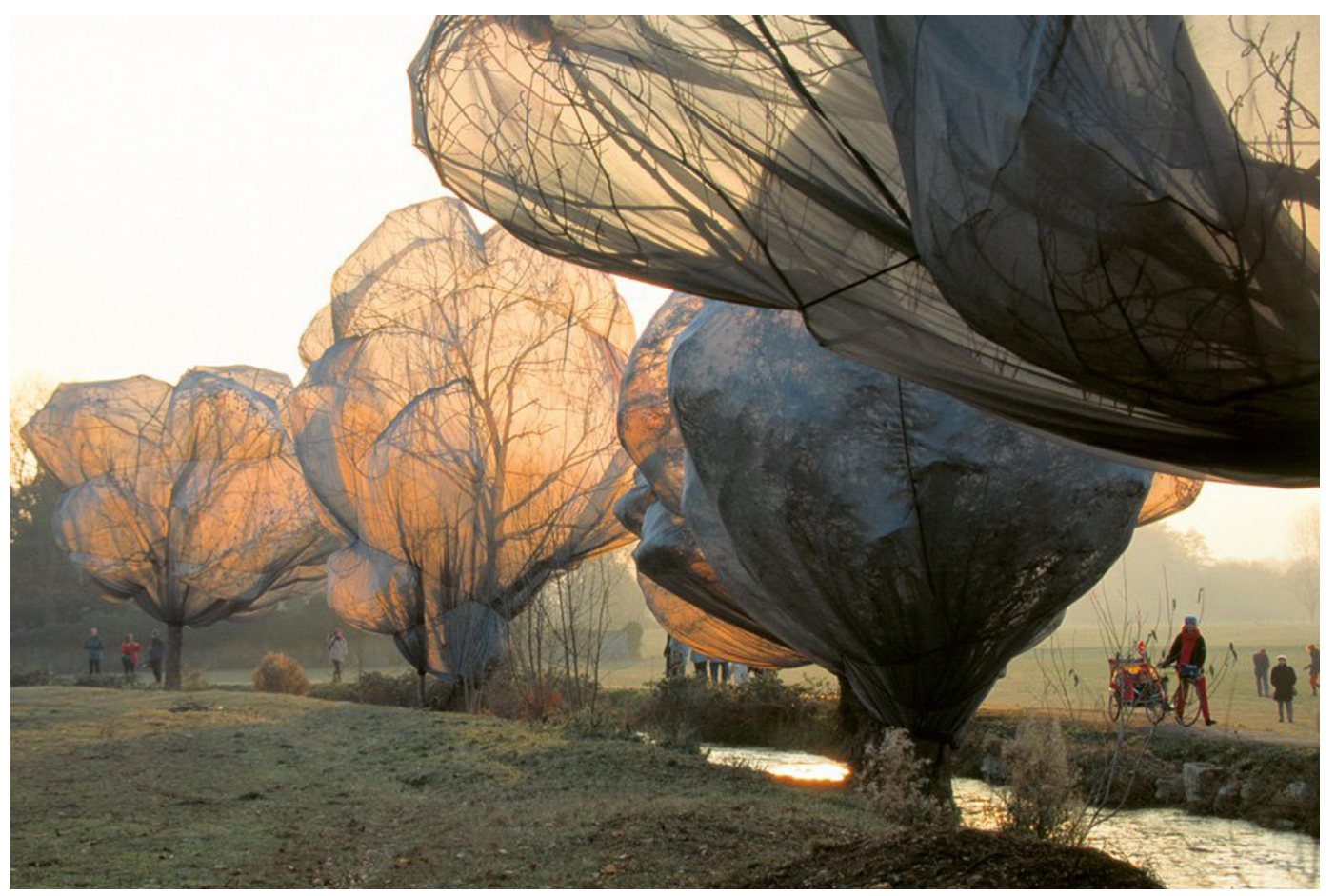

9. Wrapped Trees. Autores: Christo y Jeanne Claude (1997-1998). En: christojeanneclaude (web)

del mismo modo que disminuye cuando se rompe parcialmente la estructura de la que parte.

Nuestra arquitectura, limitada por elementos tan tectónicos como el hormigón, el ladrillo o la piedra impide una flexibilidad física, el ensanchamiento o decrecimiento del volumen espacial que encierra en función de las necesidades de este. Fijémonos en la semejanza entre la obra de Christo y Jeanne-Claude [9] y el telar de unas arañas en Pakistán [10]. Ambas son imágenes sorprendentes, dibujan el volumen que ocupan los árboles; una, la de las arañas, por necesidad $^{3}$, otra, la de los artistas, por sensibilidad poética. En ambos, el viento, el crecimiento del propio árbol o la caída de una rama es asumido por esa fina envolvente. Teniendo en cuenta este flexible mundo de telares sobre un elemento en crecimiento podríamos crear una fina envolvente translúcida, al tiempo que flexible (como las telas que envuelven nuestros invernaderos o las mallas con las que formamos alambradas) que nos ayuden a asumir los cambios constantes que existen, por ejemplo, en las viviendas.

El modelo actual de vivienda es, como nuestro tiempo, cambiante. Las familias a lo largo del tiempo van permu- tando. Las formadas por dos individuos (teniendo en cuenta el modelo más tradicional) aumentan cuando tienen hijos. Cuando estos crecen la casa necesita ensanchar; del mismo modo, cuando los hijos se emancipan la casa necesita disminuir su tamaño, el espacio privativo sobra frente a otro más comunitario, el cual además adquiere protagonismo en fechas señaladas.

En una tela de araña la solución parece estar en la flexibilidad del material, del mismo modo que en la arquitectura puede estar en nuevos materiales de construcción sacados de otros contextos y reinventados en este más tectónico. El caso de la galería Kukje de SO-IL arquitectos es un buen ejemplo de una arquitectura formada por una envolvente elástica a base de acero, en ella una malla acoge un volumen interior cuya forma es independiente a la exterior, ofreciendo una especie de pleura formada, en algunos casos, por espacios de transición.

Sería fantástico aprender de aquellos nidos de araña que van mutando en función de si sobre ellos quedan atrapados o no otros insectos, de esos nidos que disminuyen en función de diversos aconteceres, en tal caso la malla elástica 
10. Nidos de arañas. Autor imagen: desconocido

(Sid -Pakistan-, 2010)

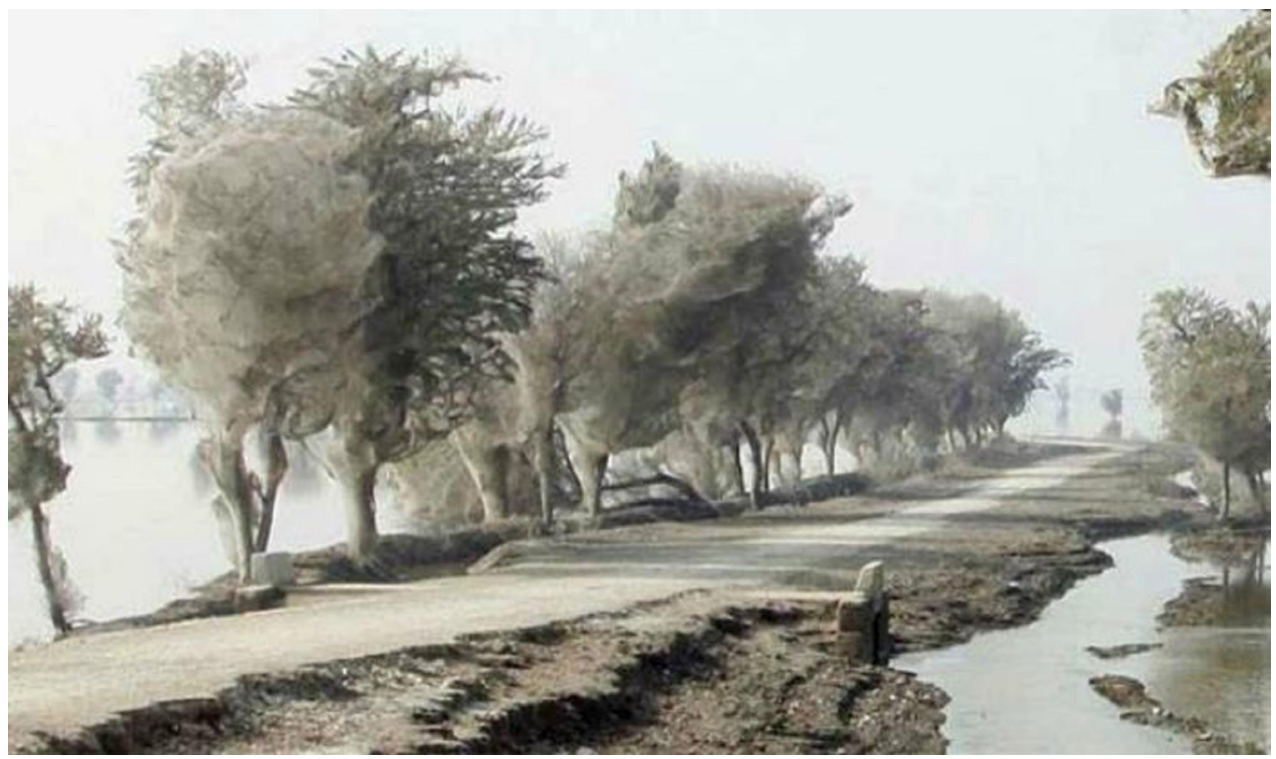

podría tener diversas formas en función de si los volúmenes interiores aumentan o disminuyen, en función de si el espacio interior acoge la flexibilidad que las telas de araña parecen adquirir a lo largo de su vida.

\section{Conclusiones}

Una mirada atenta al mundo natural nos deja ver grandes semejanzas entre el hacer arquitectónico del hombre y la construcción de refugios por parte de los animales, estas semejanzas atienden a parámetros que tiene que ver con las estructuras más profundas de la arquitectura.

En todos los casos expuestos, la relación con el lugar es vinculante. El cangrejo, el pájaro, las arañas, o las hormigas... disponen sus arquitecturas en un determinado lugar, en aquel que es óptimo según las características necesarias para su refugio. La profundidad del hueco, lo recóndito del mismo o el material de la roca son determinantes para el cangrejo, del mismo modo la humedad de la tierra lo es para las hormigas, o la altura del elemento soporte lo es para el ave que construye su nido, por lo que existe cierto instinto por parte de los animales que vincula las características del lugar con la arquitectura propuesta. De hecho, es difícil encontrar un nido de cigüeña a cota de tierra o un nido de hormigas en una superficie rocosa. La arquitectura de los animales reconoce una vincula- ción directa con el lugar poniendo este como aliado, de modo que la construcción no solo responde a sus necesidades sino a la eficiencia medida en esfuerzo y trabajo. En este sentido existe un paralelismo básico entre las construcciones animales y aquellas creadas por el hombre. A lo largo de la historia, la arquitectura, sobre todo la tradicional, ha determinado su forma, su color y sus características más vitales al lugar en la que surge. La arquitectura tradicional canaria encontraba en los muros de piedra seca la única forma de construcción para levantar las viviendas, no es arbitrario que la arquitectura de Montoro en Córdoba sea de piedra molinaza o que el Castillo de Ayud en Calatayud se confunda con la piedra de la que nace. En todas estas construcciones existe ese carácter primitivo del que gozan aún los animales, y que vincula el lugar con la propia construcción bajo unas directrices ligadas a los recursos existentes y la posibilidad de trabajar, de manera, más o menos artesanal, al tiempo que eficiente, el material. Si las primeras construcciones realizadas por el hombre están vinculadas con cuevas, con lugares horadados de forma natural que no precisaban de nada más que de una mirada atenta o la sustracción de tierra para conformar el espacio en el que habitar, las construcciones más avanzadas se servían justamente del entorno no solo para ajustarse a él sino, como aquellas aves, obtener su materia prima.

En la actualidad cabe destacar que esta mirada sostenible, en cuanto a instintiva, primigenia y vinculante al 
lugar ha ido perdiéndose en manos del hombre. Hoy se construye en desiertos con técnicas y materiales sofisticados, se rompe la piedra para sustituirla por muros de contención ignorando las características del material, su densidad, su forma o la capacidad de este para, como nos explicaba Bettini, obtener la forma arquitectónica. Es necesario, por tanto, una vuelta atrás, volver a esa vinculación intuitiva con el lugar, atender a esa mirada atenta que busca oquedades para la formalización de una arquitectura sin apenas huella ecológica, a esa otra, que recoge los residuos del entorno para construir lugares desde los que no ser vistos o a aquella que produce un material flexible que aumenta o disminuye en función de las necesidades

\section{Notas} content/218/9/1295> (fecha de consulta: 14-12-2018). 1999: 111-124). nidos tomaran los árboles para volver a formar sus nidos.

\section{Bibliografía} Universidad de Sevilla. celona. (fecha de consulta: 14-12-2018). lucía, n. ${ }^{\circ}$ 31, tercer trimestre, pp. 111-124.
De la misma manera es necesario mirar nuestro mundo contemporáneo y aplicar lo aprendido del nuevo lugar, la ciudad extensa introduce como el carácter nómada del que constantemente recorre un territorio en movimiento, porque una ciudad posee esa enorme entalpía que se traduce físicamente en la continua movilidad como base definitoria y el carácter nómada de sus habitantes, capaces de recorrer enormes distancias en cada jornada. Solo el entendimiento de la capacidad de ofrecer refugio puede cualificar los nuevos territorios urbanos.

Mirar al mundo animal de cerca nos vincula con el entorno, nos hace recuperar la salud sensitiva y entender la importancia de la búsqueda del lugar óptimo, al tiempo que potenciar nuestra capacidad creativa.

1 «Ants were capable of nest construction in all substrates tested other than completely dry or fully saturated; for a given particle size, nest volume was relatively insensitive to moisture content. Tunnels were deepest at intermediate moisture content and the maximum tunnel depth correlated with measured yield force on small rod-shaped intruders (a proxy for cohesive strength). This implies that increased cohesive strength allowed creation of tunnels that were resistant to perturbation but did not decrease individual excavation ability". MONAENKOVA, Daria, GRAVISH, Nick, RODRIGUEZ, Greggory, KUTNER, Rachel, A. D. Goodisman, Michael y I. GOLDMAN, Daniel, «Behavioral and mechanical determinants of collective subsurface nest excavation». En: <http://jeb.biologists.org/

2 «En este medio -se refiere al de aquellos rincones que se disponen en la arquitectura más tradicional y que igualmente puede atribuirse al de estas arquitecturas- las cosas aún tienen un valor de uso y nunca un valor de cambio. No existe el concepto de composición como dominio del espacio, sino el de disposición como apropiación, como utilización. El espacio resiste y gana con ella. Al espacio no se le imponen las cosas, las cosas se disponen en él» (PÉREZ,

3 En el año 2010 la provincia de Sid en Pakistán fue inundada por causas naturales en más de una quinta parte de su superficie lo que provocó que los arác-

ALARCÓN, Luisa (2015), El proyecto arquitectónico como investigación: Una intervención en el territorio. El arroyo judío. Tesis doctoral inédita,

BETTINI, Sergio (1963-2003), El espacio arquitectónico. De Roma a Bizancio, Nobuko S. A., Florida.

DE SOLÁ, Ignasi (2000), «Removiendo la superficie», en CONDE, Yago, Arquitectura de la Indeterminación, Actar, Barcelona.

LOUBES, J. P. (1985), Arquitectura subterránea. Aproximación a un hábitat natural, Colección Tecnología y Arquitectura, Gustavo Gili, Bar-

MONAENKOVA, Daria, GRAVISH, Nick, RODRIGUEZ, Greggory, KUTNER, Rachel, A. D. GOODISMAN, Michael e I. GOLDMAN, Daniel, «Behavioral and mechanical determinants of collective subsurface nest excavation». En: <http://jeb.biologists.org/content/218/9/1295>

PÉREZ, Mariano (1999), «Epitafio a la arquitectura tradicional. Encuentro con el aporisma», Demófilo. Revista cultural tradicional de Anda- 